\title{
SOCIEDAD DE CIRUJANOS Y EL DESAFÍO ACTUAL
}

\author{
Society of surgeons and the current challenge
}

Después de asumir como presidente en noviembre pasado, quiero en forma resumida, destacar algunos de los elementos del programa que presenté en mi candidatura.

Sin perder la perspectiva de que la SCCH es fundamentalmente una asociación académica, con actividades periódicas que incluyen: las organizadas por los departamentos que componen nuestra sociedad, que se realizan especialmente en regiones y que permiten la participación e interacción de los miembros que compartimos el interés en el tema tratado como parte de una subespecialidad; por otra parte, se incluyen también, las actividades y reuniones mensuales que se realizan en Santiago y que han tenido posibilidad de transmitirse a regiones en forma simultánea a través de la red en algunas ciudades de nuestro país. En el contexto se incluye además el congreso anual, que es sin duda la principal actividad académica y que cada año procura contar con destacados especialistas nacionales e internacionales sobre los temas centrales del congreso.

Sin embargo, en los últimos años, la situación gremial se ha transformado también en una cuestión prioritaria de nuestra actividad. Cada vez más, instituciones de salud, tanto privadas como públicas, han tomado el control casi total de la gestión de ella. Estas controlan, por una parte, al paciente, obligándolo a ser atendido y tratado donde lo determinen, dejando de lado por ejemplo lo que era el espíritu de la ley de Isapres: la libre elección. Y por otro lado, nos controlan a nosotros los médicos en general y a los cirujanos en particular, manejando los honorarios médicos quirúrgicos a su antojo. En otras palabras, lo que era el eje central de la acción médica: la relación médico paciente, ha pasado a ser poco relevante en el escenario actual y ser sólo un insumo más dentro de este gran negocio en que se ha transformado la salud.

Por ello creo firmemente en la necesidad de tomar protagonismo en este aspecto, para lo cual es fundamental que nuestra sociedad agrupe, sino a todos, a la gran mayoría de los cirujanos del país para enfrentar esta situación, en forma cohesionada, en el escenario actual en el que nos vemos envueltos. Para esto, es importante actualizar los distintos procedimientos quirúrgicos que realizamos hoy, que no son los mismos de hace décadas cuando se creó el denominado arancel Fonasa, valorizarlos adecuadamente, hacer que se respeten por las instituciones encargadas de reembolsarlos y volver a situar la relación médico paciente como eje central de la actividad quirúrgica.

Es mi propósito, junto al directorio que me acompaña, trabajar fuertemente en este aspecto, sin perder la perspectiva que lo académico es lo que nos convoca; desde ya quiero invitar a todos a nuestro congreso anual que se realizará en el mes de noviembre en la ciudad de Pucón.

Aprovecho la oportunidad para saludarlos en este año que se inicia, deseándoles un gran año 2015 junto a sus seres queridos.

Un abrazo a todos los que formamos parte de la familia quirúrgica del país.

Dr. Juan Carlos Díaz J. Presidente de la Sociedad de Cirujanos de Chile 